\title{
Morin exerts cytoprotective effects against oxidative stress in C2C12 myoblasts via the upregulation of Nrf2-dependent HO-1 expression and the activation of the ERK pathway
}

\author{
MOON HEE LEE ${ }^{1,2}$, MIN HO HAN ${ }^{3}$, DAE-SUNG LEE ${ }^{3}$, CHEOL PARK $^{4}$, SU-HYUN HONG ${ }^{1}$, GI-YOUNG KIM ${ }^{5}$,

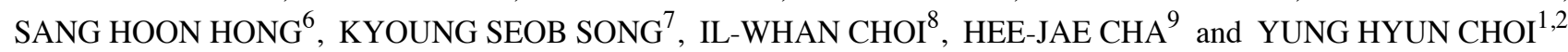 \\ ${ }^{1}$ Department of Biochemistry, Dongeui University College of Korean Medicine, Busan 614-052; \\ ${ }^{2}$ Anti-Aging Research Center, Dongeui University, Busan 614-714; ${ }^{3}$ Marine Biodiversity Institute of Korea,
} Seocheon 325-902; ${ }^{4}$ Department of Molecular Biology, College of Natural Sciences and Human Ecology, Dongeui University, Busan 614-714; ${ }^{5}$ Laboratory of Immunobiology, Department of Marine Life Sciences, Jeju National University, Jeju 690-756; ${ }^{6}$ Department of Internal Medicine, Dongeui University College of Korean Medicine, Busan 614-052; ${ }^{7}$ Department of Physiology, Kosin University College of Medicine, Busan 602-072; ${ }^{8}$ Department of Microbiology, College of Medicine, Inje University, Busan 608-737; ${ }^{9}$ Department of Parasitology and Genetics, Kosin University College of Medicine, Busan 602-072, Republic of Korea

Received February 4, 2016; Accepted December 8, 2016

DOI: $10.3892 /$ ijmm.2016.2837

\begin{abstract}
In the present study, we investigated the cytoprotective efficacy of morin, a natural flavonoid, against oxidative stress and elucidated the underlying mechanisms in $\mathrm{C} 2 \mathrm{C} 12$ myoblasts. Our results indicated that morin treatment prior to hydrogen peroxide $\left(\mathrm{H}_{2} \mathrm{O}_{2}\right)$ exposure significantly increased cell viability and prevented the generation of reactive oxygen species. $\mathrm{H}_{2} \mathrm{O}_{2}$-induced comet-like DNA formation and $\gamma \mathrm{H} 2 \mathrm{AX}$ phosphorylation were also markedly suppressed by morin with a parallel inhibition of apoptosis in $\mathrm{C} 2 \mathrm{C} 12$ myoblasts, suggesting that morin prevented $\mathrm{H}_{2} \mathrm{O}_{2}$-induced cellular DNA damage. Furthermore, morin markedly enhanced the expression of heme oxygenase-1 (HO-1) associated with the induction and phosphorylation of nuclear factor-erythroid 2-related factor 2 (Nrf2) and the inhibition of Kelch-like ECH-associated protein 1 (Keap1) expression. Notably, these events were eliminated by transient transfection with Nrf2-specific small interfering RNA. Additional experiments demonstrated that the activation of the Nrf2/HO-1 pathway by morin was
\end{abstract}

Correspondence to: Dr Hee-Jae Cha, Department of Parasitology and Genetics, Kosin University College of Medicine, Gamcheollo 262, Seo-gu, Busan 602-072, Republic of Korea

E-mail: hcha@kosin.ac.kr

Dr Yung Hyun Choi, Department of Biochemistry, Dongeui University College of Korean Medicine, Yangjeong-dong San 45, Busanjin-gu, Busan 614-052, Republic of Korea

E-mail: choiyh@deu.ac.kr

Key words: morin, reactive oxygen species, nuclear factor-erythroid 2-related factor 2, heme oxygenase-1, extracellular signal-regulated kinase mediated by the extracellular signal-regulated kinase (ERK) signaling cascade. This phenomenon was confirmed with suppressed Nrf2 phosphorylation and consequently diminished HO-1 expression in cells treated with a pharmacological inhibitor of ERK. Collectively, these results demonstrated that morin augments the cellular antioxidant defense capacity through the activation of Nrf2/HO-1 signaling, which involves the activation of the ERK pathway, thereby protecting $\mathrm{C} 2 \mathrm{C} 12$ myoblasts from $\mathrm{H}_{2} \mathrm{O}_{2}$-induced oxidative cytotoxicity.

\section{Introduction}

Dysregulation of antioxidant mechanisms along with excessive accumulation of reactive oxygen species (ROS) is causally linked to various health issues, including muscular dystrophy and sarcopenia $(1,2)$. Within the healthy muscle cell, ROS are generated as both a by-product of metabolism and as effectors of signaling cascades (3). However, excessive ROS generation in skeletal muscles can influence their contractile function by causing fatigue and increasing the oxidative damage to cells $(4,5)$. Therefore, increasing the antioxidant capacity of skeletal muscles can be beneficial for muscle performance, disease prevention, and improved quality of life.

Many flavonoids, which are polyphenolic compounds commonly found in a variety of fruits and vegetables and as components of dietary supplements containing herbs, have been shown to protect cells against oxidative stress-induced damage by virtue of their antioxidant properties (6-8). Morin $(3,5,7,2$ ',4'-pentahydroxyflavone) is a naturally occurring flavonoid that consists of a yellowish pigment found in many fruits and herbs $(9,10)$. It has been reported that this compound may possess strong antioxidant properties that protect cells against oxidative-induced damage (10-13). Morin has also been shown to induce the activity of phase II enzymes, such as quinone reduc- 
tase, glutathione S-transferase, and glutathione reductase (14-17). In particular, morin has been reported to protect human lens epithelial cells against oxidative stress through the activation of nuclear factor erythroid 2-related factor 2 (Nrf2)-dependent heme oxygenase-1 (HO-1) expression (18). However, the inhibitory mechanisms of morin vis-à-vis the beneficial effect of morin against oxidative stress have not been fully studied to date.

Under normal conditions, Nrf2, a transcription factor ubiquitously expressed in most tissues, is bound to Kelch-like ECH-associated protein 1 (Keap1) in the cytoplasm $(19,20)$. Phase II enzyme inducers can disrupt the Nrf2/Keap1 complex, resulting in the release of $\mathrm{Nrf} 2$ and its subsequent translocation to the nucleus $(20,21)$. In the nucleus, Nrf2 activates the antioxidant response element (ARE), which transcriptionally activates many antioxidative genes $(20,22)$. It has recently been reported that activation of the $\mathrm{Nrf} 2 / \mathrm{HO}-1$ pathway can be increased by the stabilization and/or phosphorylation of the Nrf2 protein, and several signaling molecules, including phosphatidylinositol-3-kinase (PI3K)/Akt and mitogen-activated protein kinases (MAPKs), have been shown to participate in the processes in response to a variety of phase II gene inducers $(23,24)$. Therefore, targeted activation of Nrf2/HO-1 signaling may be considered an important therapeutic strategy for protection against oxidative damage $(19,20)$. In the present study, we investigated the cytoprotective effect of morin against oxidative stress damage in a mouse myoblast $\mathrm{C} 2 \mathrm{C} 12$ cell line and the possible protective mechanisms involved.

\section{Materials and methods}

Reagents and antibodies. Dulbecco's modified Eagle's medium (DMEM), fetal bovine serum (FBS), and penicillin/streptomycin antibiotics were purchased from WelGENE Inc. (Daegu, Republic of Korea). Morin, 3-[4,5-dimethylthiazol-2-yl)2,5-diphenyltetrazolium bromide (MTT), N-acetyl-Lcysteine (NAC), 4,6-diamidino-2-phenyllindile (DAPI), and PD98059 (2'-amino-3'-methoxyflavone) were obtained from Sigma-Aldrich Chemical Co. (St. Louis, MO, USA). 2',7'-Dichlorodihydrofluorescein diacetate (DCF-DA) and a fluorescein-conjugated Annexin V (Annexin V-FITC) staining assay kit were purchased from Molecular Probes (Eugene, OR, USA) and BD Biosciences (San Jose, CA, USA), respectively. An enhanced chemiluminescence (ECL) detection kit and FITC-conjugated donkey anti-rabbit IgG were purchased from Amersham Co. (Arlington Heights, IL, USA) and Jackson ImmunoResearch Laboratories Inc. (West Grove, PA, USA), respectively. Various primary antibodies (Table I) for western blot analysis were obtained from Cell Signaling Technology, Inc. (Boston, MA, USA), Santa Cruz Biotechnology, Inc. (Santa Cruz, CA, USA) and Abcam, Inc. (Cambridge, MA, USA). Horseradish peroxidase-conjugated anti-rabbit (SC-2004), anti-mouse (SC-2005) and anti-goat (SC-2350) antibodies were used as the secondary antibodies, which were obtained from Santa Cruz Biotechnology, Inc. All other chemicals were purchased from Sigma-Aldrich Chemical Co.

Cell culture and MTT assay. C2C12 myoblasts obtained from the American Type Culture Collection (ATCC, Manassas, VA, USA) were grown in DMEM supplemented with $10 \%$ FBS and $100 \mu \mathrm{g} / \mathrm{ml}$ penicillin/streptomycin antibiotics in a humidified
$5 \% \mathrm{CO}_{2}$ atmosphere at $37^{\circ} \mathrm{C}$. Morin was dissolved in dimethyl sulfoxide (DMSO) and adjusted to final concentrations using complete DMEM prior to use; the final DMSO concentration was $<0.1 \%$ in all experiments. In order to evaluate the degree to which a single morin treatment affects $\mathrm{C} 2 \mathrm{C} 12$ cell viability, the $\mathrm{C} 2 \mathrm{C} 12$ cells were seeded at a density of $1 \times 10^{4}$ cells/well in a 96-well plate, incubated at $37^{\circ} \mathrm{C}$ for $24 \mathrm{~h}$, and treated with morin at different concentrations (100-10,000 $\mu \mathrm{M})$. Additional cell cultivation occurred for $6 \mathrm{~h}$ in media where $\mathrm{H}_{2} \mathrm{O}_{2}$ and NAC were simultaneously administered, singularly administered, or were not administered. For the cell viability assay using a colorimetric MTT assay, the medium was discarded, MTT solution was added to each well, and the cells were further incubated for $3 \mathrm{~h}$ at $37^{\circ} \mathrm{C}$. The medium was discarded and DMSO was added to dissolve the formazan product. The optical density was then read at $450 \mathrm{~nm}$ using an enzyme-linked immunosorbent assay (ELISA) plate reader (Dynatech MR-7000; Dynatech Laboratories, Chantilly, VA, USA). Relative cell cytotoxicity was evaluated according to the quantity of MTT converted to insoluble formazan salt.

Intracellular ROS measurement. In order to monitor ROS generation, the cells were incubated with $10 \mu \mathrm{M}$ DCF-DA for $20 \mathrm{~min}$ at room temperature in the dark. The ROS production in the cells was monitored with a flow cytometer (Becton-Dickinson, San Jose, CA, USA) using CellQuest Pro software (25).

Determination of apoptotic cells by flow cytometry. To quantitatively assess the induced cell apoptosis rate, an Annexin V-FITC staining assay was performed as previously described (26). The cells were washed twice with ice-cold phosphate-buffered saline (PBS) and stained with Annexin V-FITC and propidium iodide (PI) in each sample for $15 \mathrm{~min}$ at room temperature in the dark. The degree of apoptosis was quantified as a percentage of Annexin V-positive and PI-negative (Annexin $\mathrm{V}^{+} / \mathrm{PI}^{-}$cells) cells using a flow cytometer.

Comet assay. To assess oxidative DNA damage, the cell suspension was mixed with $0.5 \%$ low melting agarose (LMA) at $37^{\circ} \mathrm{C}$, and the mixture was spread on a fully frosted microscopic slide precoated with $1 \%$ normal melting agarose. After the solidification of the agarose, the slide was covered with $0.5 \%$ LMA and then immersed in a lysis solution $(2.5 \mathrm{M} \mathrm{NaCl}, 100 \mathrm{mM}$ Na-ethylenediaminetetraacetic acid (Na-EDTA), $10 \mathrm{mM}$ Tris, $1 \%$ Triton $\mathrm{X}-100$, and $10 \%$ DMSO, $\mathrm{pH} 10.0$ ) for $1 \mathrm{~h}$ at $4{ }^{\circ} \mathrm{C}$. The slides were then placed in a gel electrophoresis apparatus containing $300 \mathrm{mM} \mathrm{NaOH}$ and $10 \mathrm{mM}$ Na-EDTA (pH 13.0) for $40 \mathrm{~min}$ to allow for DNA unwinding and the expression of alkalilabile damage. Next, an electrical field was applied $(300 \mathrm{~mA}$, $25 \mathrm{~V}$ ) for $20 \mathrm{~min}$ at $4^{\circ} \mathrm{C}$ to draw the negatively charged DNA toward the anode. After electrophoresis, the slides were washed three times for $5 \mathrm{~min}$ at $4^{\circ} \mathrm{C}$ in a neutralizing buffer ( $0.4 \mathrm{M}$ Tris, $\mathrm{pH} 7.5)$, followed by staining with $20 \mu \mathrm{g} / \mathrm{ml}$ PI. The cells were washed twice with PBS, and images were then captured using a fluorescence microscope (Carl Zeiss, Jena, Germany) (27).

Protein extraction and western blot analysis. Whole-cell protein extracts from $\mathrm{C} 2 \mathrm{C} 12$ myoblasts were prepared with cell lysis buffer [25 mM of Tris- $\mathrm{Cl}$ (pH 7.5), $250 \mathrm{mM}$ of $\mathrm{NaCl}, 5 \mathrm{mM}$ of EDTA, $1 \%$ Nonidet P-40, $0.1 \mathrm{mM}$ of sodium orthovanadate, $2 \mu \mathrm{g} / \mathrm{ml}$ of leupeptin, and $100 \mu \mathrm{g} / \mathrm{ml}$ of phenylmethylsulfonyl 
Table I. Antibodies used in the present study.

\begin{tabular}{|c|c|c|c|}
\hline Antibody & Origin & Company & Catalogue no. \\
\hline Actin & Mouse monoclonal & Santa Cruz Biotechnology, Inc. & SC-47778 \\
\hline $\mathrm{p}-\gamma \mathrm{H} 2 \mathrm{AX}$ & Rabbit monoclonal & Cell Signaling Technology, Inc. & 9718 \\
\hline$\gamma \mathrm{H} 2 \mathrm{AX}$ & Rabbit monoclonal & Cell Signaling Technology, Inc. & 7631 \\
\hline $\mathrm{p}-\mathrm{Nrf} 2$ & Rabbit monoclonal & Abcam, Inc. & $a b 76026$ \\
\hline Nrf2 & Rabbit polyclonal & Santa Cruz Biotechnology, Inc. & SC-13032 \\
\hline Keap1 & Goat polyclonal & Santa Cruz Biotechnology, Inc. & SC-15246 \\
\hline $\mathrm{HO}-1$ & Rabbit polyclonal & Santa Cruz Biotechnology, Inc. & SC-10789 \\
\hline NQO1 & Goat polyclonal & Santa Cruz Biotechnology, Inc. & SC-16464 \\
\hline TrxR1 & Mouse monoclonal & Santa Cruz Biotechnology, Inc. & SC-28321 \\
\hline Lamin B & Goat polyclonal & Santa Cruz Biotechnology, Inc. & SC-6216 \\
\hline $\mathrm{p}-\mathrm{PI} 3 \mathrm{~K}$ & Rabbit polyclonal & Cell Signaling Technology, Inc. & 4228 \\
\hline PI3K & Rabbit polyclonal & Cell Signaling Technology, Inc. & 4249 \\
\hline p-Akt & Rabbit polyclonal & Santa Cruz Biotechnology, Inc. & SC-101629 \\
\hline Akt & Rabbit polyclonal & Santa Cruz Biotechnology, Inc. & SC-8312 \\
\hline p-ERK & Mouse monoclonal & Cell Signaling Technology, Inc. & 9106 \\
\hline ERK & Rabbit polyclonal & Santa Cruz Biotechnology, Inc. & $\mathrm{SC}-154$ \\
\hline p-JNK & Mouse monoclonal & Cell Signaling Technology, Inc. & 9255 \\
\hline JNK & Rabbit monoclonal & Cell Signaling Technology, Inc. & 9252 \\
\hline p-p38 MAPK & Rabbit monoclonal & Cell Signaling Technology, Inc. & 9211 \\
\hline p38 MAPK & Rabbit polyclonal & Santa Cruz Biotechnology, Inc. & SC-535 \\
\hline
\end{tabular}

flouride] containing protease inhibitor cocktail tablets (Roche Diagnostics, Mannheim, Germany) for $30 \mathrm{~min}$. In a parallel experiment, nuclear and cytosolic proteins were prepared using nuclear extraction reagents (Pierce Biotechnology, Rockford, IL, USA) according to the manufacturer's protocol. After cell debris was discarded following centrifugation at $13,000 \mathrm{x} \mathrm{g}$ for $15 \mathrm{~min}$, the protein concentration was determined using the Bio-Rad protein assay kit (Bio-Rad Laboratories, Hercules, CA, USA). For western blot analysis, equal amounts of protein extracts were subjected to electrophoresis on sodium dodecyl sulfate (SDS) polyacrylamide gels and transferred onto nitrocellulose membranes (Schleicher and Schuell Bioscience, Inc., Keene, NH, USA) by electroblotting. The blots were probed with the desired primary antibodies for $1 \mathrm{~h}$, incubated with the diluted enzyme-linked secondary antibodies, and visualized using an ECL method according to the recommended procedure.

Small interfering RNA (siRNA) transfection. Nrf2 siRNA and control siRNA were purchased from Santa Cruz Biotechnology, Inc. The siRNAs were transfected into cells according to the manufacturer's instructions using Lipofectamine 2000 Transfection Reagent (Life Technologies, Carlsbad, CA, USA). For transfection, the cells were seeded in 6-well culture plates and incubated with the control siRNA or Nrf2 siRNA at $50 \mathrm{nM}$ for $6 \mathrm{~h}$ in serum-free Opti-MEM media (Life Technologies). After incubation, the transfected cells were subjected to treatment, as previously described (28).

Immunofluorescent staining for $\mathrm{Nrf2}$. C2C12 cells were seeded on glass coverslips in 6-well plates for $24 \mathrm{~h}$, and the cells were treated with morin for $6 \mathrm{~h}$. Next, the cells were rinsed twice with PBS and fixed with $3.7 \%$ paraformaldehyde in PBS for 10 min at $4^{\circ} \mathrm{C}$. The cells were incubated with $0.4 \%$ Triton $\mathrm{X}-100$ for $10 \mathrm{~min}$ and then blocked with $5 \%$ bovine serum albumin for $1 \mathrm{~h}$, followed by probing with the anti-Nrf2 antibody overnight at $4^{\circ} \mathrm{C}$ and incubation with FITC-conjugated donkey anti-rabbit IgG for $2 \mathrm{~h}$ at room temperature. After washing with PBS, nuclei were counterstained with DAPI solution $(1 \mathrm{mg} / \mathrm{ml})$ for $15 \mathrm{~min}$ in the dark. Images were collected using a fluorescence microscope (Carl Zeiss, Oberkochen, Germany).

Statistical analysis. Data are expressed as mean \pm standard deviation (SD) from at least three independent experiments. Statistical comparisons between different groups were performed using one-way ANOVA, followed by Student's t-tests after comparing each treated group to the negative control. Probability values $\mathrm{P}<0.01$ were considered to indicate statistically significant differences.

\section{Results}

Effects of morin on $\mathrm{H}_{2} \mathrm{O}_{2}$-induced cytotoxicity in $\mathrm{C} 2 \mathrm{Cl}$ myoblasts. To evaluate the protective effect of morin on $\mathrm{H}_{2} \mathrm{O}_{2}$-induced cytotoxicity, the cells were treated with various concentrations of morin for $24 \mathrm{~h}$, and the cell viability was evaluated for primary dose selection by determining the percentage of MTT reduction. Morin alone at $100-500 \mu \mathrm{M}$ showed no cytotoxic effects, but significant cytotoxicity was noted at $1,000 \mu \mathrm{M}$ morin (Fig. 1A). Thus, $500 \mu \mathrm{M}$ morin was chosen as the optimal dose for studying the cytoprotective effect of this flavonoid.

The viability of the $\mathrm{C} 2 \mathrm{C} 12$ cells when exposed to $\mathrm{H}_{2} \mathrm{O}_{2}$ at the concentration of $1 \mathrm{mM}$ for $6 \mathrm{~h}$ was significantly decreased as compared with the control group, and the survival rate was $\sim 60 \%$ that of the control group. When the $\mathrm{C} 2 \mathrm{C} 12$ cells were pretreated 

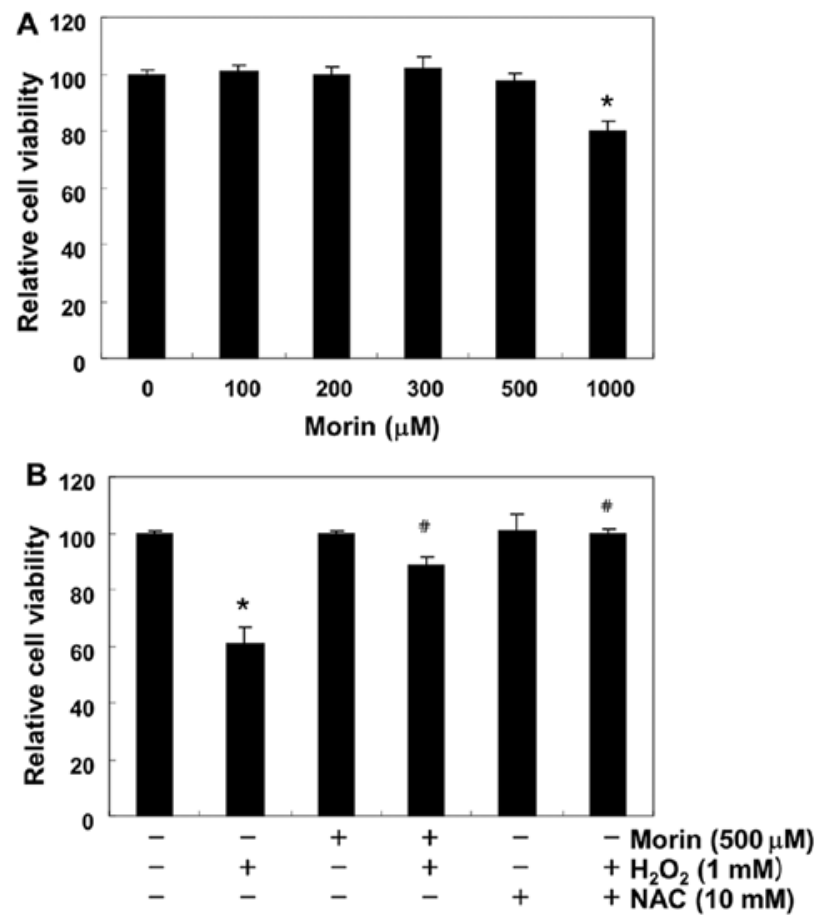

Figure 1. Morin attenuates $\mathrm{H}_{2} \mathrm{O}_{2}$-induced growth inhibition in $\mathrm{C} 2 \mathrm{C} 12$ myoblasts. Cells were (A) treated with various concentrations of morin for $24 \mathrm{~h}$ or (B) pretreated with $500 \mu \mathrm{M}$ morin or $10 \mathrm{mM} \mathrm{N}$-acetyl-L-cysteine (NAC) for $1 \mathrm{~h}$ and then stimulated with or without $1 \mathrm{mM} \mathrm{H}_{2} \mathrm{O}_{2}$ for $6 \mathrm{~h}$. The cell viability was assessed using an MTT reduction assay. The results are the mean \pm SD values obtained in three independent experiments (" $\mathrm{P}<0.05$ compared with the control group; ${ }^{*} \mathrm{P}<0.05$ compared with the $\mathrm{H}_{2} \mathrm{O}_{2}$-treated group).

with $500 \mu \mathrm{M}$ morin or $10 \mathrm{mM}$ NAC, an ROS scavenger that was used as positive control, for $1 \mathrm{~h}$ and exposed to $\mathrm{H}_{2} \mathrm{O}_{2}$ for an additional $6 \mathrm{~h}$, the cell viability was significantly increased compared to the $\mathrm{H}_{2} \mathrm{O}_{2}$ group, and the survival rate was 81.00 and $99.08 \%$ that of the control group, respectively (Fig. 1B).

Inhibition of $\mathrm{H}_{2} \mathrm{O}_{2}$-induced $\mathrm{ROS}$ production by morin in C2C12 myoblasts. As the cytotoxicity of $\mathrm{H}_{2} \mathrm{O}_{2}$ is mainly mediated by oxidative stress, we investigated the effect of morin on $\mathrm{H}_{2} \mathrm{O}_{2}$-induced ROS accumulation using DCF-DA reagent. Compared with the non-treated control cells, the level of intracellular ROS was markedly increased in the $\mathrm{C} 2 \mathrm{C} 12$ cells treated with $1 \mathrm{mM} \mathrm{H}_{2} \mathrm{O}_{2}$ for $6 \mathrm{~h}$, as indicated by the increase in the DCF-liberated fluorescent signal (Fig. 2A). However, when the $\mathrm{C} 2 \mathrm{C} 12$ cells were pretreated with morin or NAC, the ROS formation was significantly decreased, suggesting that morin pretreatment induced a cellular antioxidative response.

Protection against $\mathrm{H}_{2} \mathrm{O}_{2}$-induced $\mathrm{C} 2 \mathrm{C} 12$ cell apoptosis by morin. The effects of morin on $\mathrm{C} 2 \mathrm{C} 12$ cell apoptosis induced by $\mathrm{H}_{2} \mathrm{O}_{2}$ were observed using an Annexin V-FITC/PI assay. As illustrated in Fig. 2B, the percentage of apoptotic cells treated with $1 \mathrm{mM} \mathrm{H}_{2} \mathrm{O}_{2}$ was $49.54 \%$; however, morin or NAC pretreatment effectively decreased cell apoptosis induced by $\mathrm{H}_{2} \mathrm{O}_{2}$ to 7.99 and $7.86 \%$, respectively. The results indicate that the $\mathrm{H}_{2} \mathrm{O}_{2}$-induced apoptosis was mediated by ROS generation and that morin exerted a potent ROS scavenging effect, preventing $\mathrm{H}_{2} \mathrm{O}_{2}$-induced apoptosis.
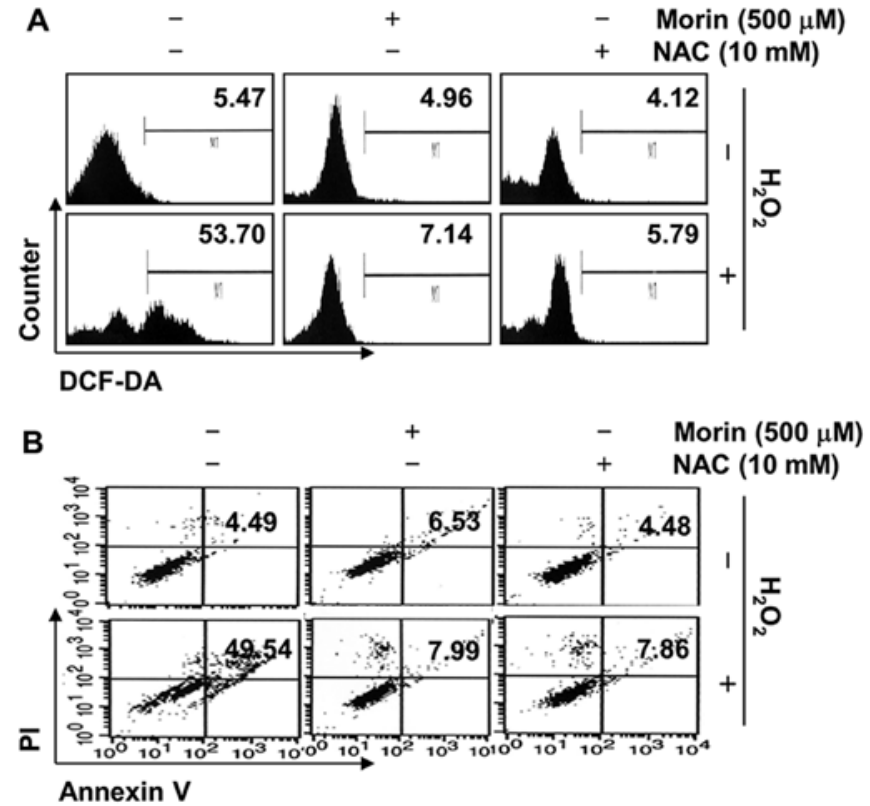

Figure 2. Morin blocks $\mathrm{H}_{2} \mathrm{O}_{2}$-induced reactive oxygen species (ROS) generation and apoptosis in $\mathrm{C} 2 \mathrm{C} 12$ myoblasts. Cells were pretreated with $500 \mu \mathrm{M}$ morin or $10 \mathrm{mM} \mathrm{N}$-acetyl-L-cysteine (NAC) for $1 \mathrm{~h}$ and then stimulated with and without $1 \mathrm{mM} \mathrm{H} \mathrm{O}_{2}$ for $6 \mathrm{~h}$. (A) In order to monitor ROS production, the cells were incubated at $37^{\circ} \mathrm{C}$ in the dark for $20 \mathrm{~min}$ with culture medium containing $10 \mu \mathrm{M}$ DCF-DA. ROS generation was evaluated using a flow cytometer. (B) The cells were stained with Annexin V-FITC and propidium iodide (PI), and the percentages of apoptotic cells (Annexin $\mathrm{V}^{+} / \mathrm{PI}^{-}$cells) were then analyzed using a flow cytometer. Data are the mean of two different experiments.

Prevention of $\mathrm{H}_{2} \mathrm{O}_{2}$-induced DNA damage by morin in C2C12 myoblasts. We next examined the effects of morin on $\mathrm{H}_{2} \mathrm{O}_{2}$-mediated DNA damage in the $\mathrm{C} 2 \mathrm{C} 12$ cells using the comet assay (single cell gel electrophoresis) and western blot analysis. Exposure to $\mathrm{H}_{2} \mathrm{O}_{2}$ alone induced significant DNA breaks, resulting in an increase in fluorescence intensity in the tails of the comet-like structures (Fig. 3A); however, this adverse effect was markedly reduced by pretreatment with morin or NAC. In addition, the exposure of the $\mathrm{C} 2 \mathrm{C} 12$ cells to $\mathrm{H}_{2} \mathrm{O}_{2}$ resulted in upregulation in the level of the phosphorylated histone variant $\mathrm{H} 2 \mathrm{AX}(\mathrm{p}-\gamma \mathrm{H} 2 \mathrm{AX})$ at serine 139 , a sensitive marker of DNA double strand breaks (29); however, pretreatment with morin or $\mathrm{NAC}$ resulted in a significant decrease in $\mathrm{p}-\gamma \mathrm{H} 2 \mathrm{AX}$ expression.

Effects of morin on the expression of $\mathrm{Nrf} 2$ and $\mathrm{HO}-1$ in $\mathrm{C} 2 \mathrm{Cl} 2$ myoblasts. As Nrf2 signaling regulates cellular antioxidant response $(20,22)$, we examined whether morin protects cells from oxidative stress by activating the Nrf 2 signaling pathway. Our immunoblotting results indicated that treatment of $\mathrm{C} 2 \mathrm{C} 12$ cells with morin induced the expression of HO-1 protein in a time-dependent manner, but other antioxidant enzymes, NADPH-quinone oxidoreductase 1 (NQO1) and thioredoxin reductase 1 ( $\operatorname{Trx} \mathrm{R} 1$ ), were unaffected by morin treatment, which was associated with the upregulation of $\mathrm{Nrf} 2$ expression and the downregulation of Keap1 (Fig. 4A).

Since the phosphorylation of Nrf2 at Ser40 by several kinases is also a critical process in its stabilization and nuclear translocation $(20,23,24)$, we examined the phosphorylation of Nrf2 under morin treatment to further confirm the Nrf2 activating property 

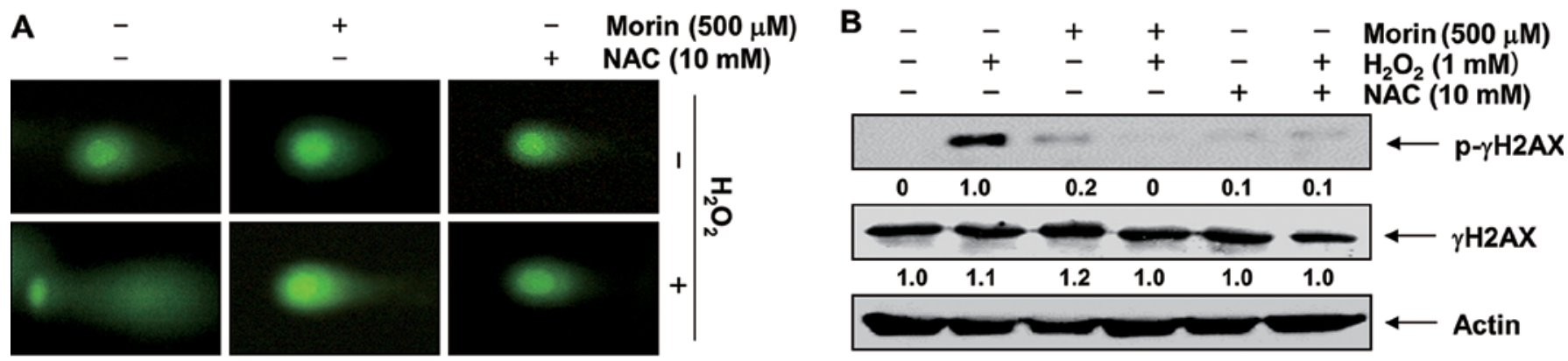

Figure 3. Morin protects against $\mathrm{H}_{2} \mathrm{O}_{2}$-induced DNA damage in $\mathrm{C} 2 \mathrm{C} 12$ myoblasts. Cells were pretreated with $500 \mu \mathrm{M}$ morin or $10 \mathrm{mM} N$-acetyl-L-cysteine (NAC) for $1 \mathrm{~h}$ and then stimulated with and without $1 \mathrm{mM} \mathrm{H}_{2} \mathrm{O}_{2}$ for $6 \mathrm{~h}$. (A) To detect cellular DNA damage, the comet assay was performed, and representative images of the comets were captured using a fluorescence microscope (x400 original magnification). (B) The cells were lysed and then equal amounts of cell lysates were separated on sodium dodecyl sulfate (SDS)-polyacrylamide gels and transferred to nitrocellulose membranes. The membranes were probed with specific antibodies against $\mathrm{p}-\gamma \mathrm{H} 2 \mathrm{AX}, \gamma \mathrm{H} 2 \mathrm{AX}$, and actin as an internal control, and the proteins were visualized using an enhanced chemiluminescence (ECL) detection system. The relative ratios of expression in the western blotting results are shown at the bottom of each of the results as relative values to actin expression.
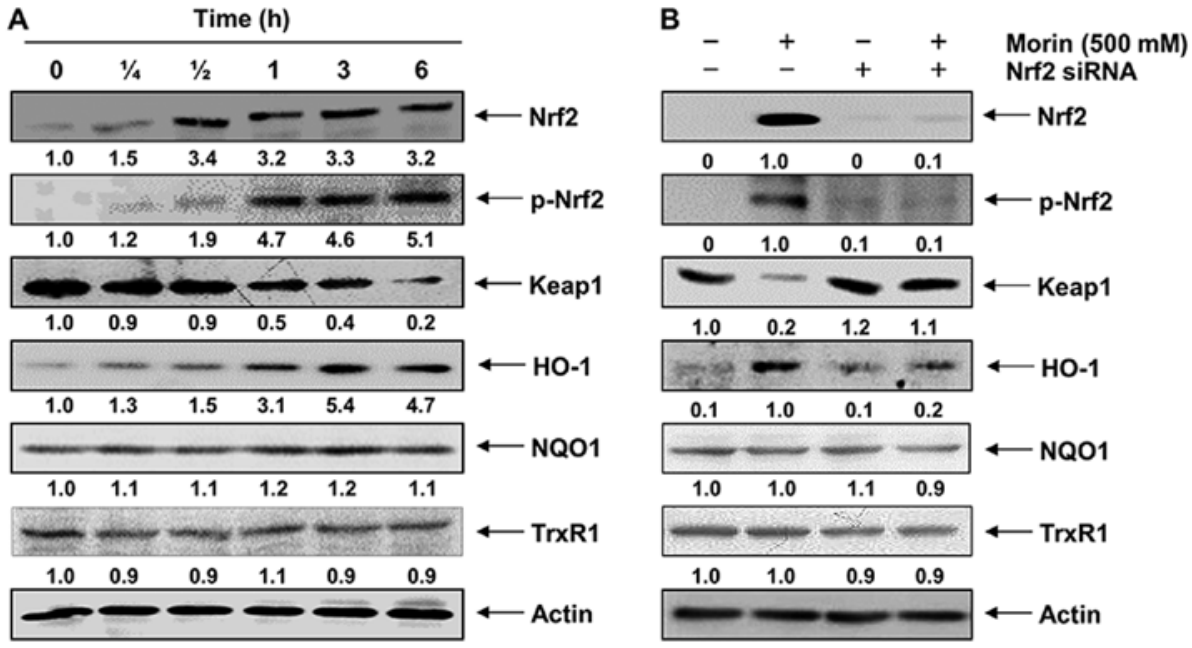

Figure 4. Morin induces nuclear factor-erythroid 2-related factor 2 (Nrf2)-dependent heme oxygenase-1 (HO-1) expression in C2C12 myoblasts. (A) Cells were incubated with $500 \mu \mathrm{M}$ morin for the indicated time periods. The cells were lysed and then equal amounts of cell lysates were separated on sodium dodecyl sulfate (SDS)-polyacrylamide gels and transferred to nitrocellulose membranes. (B) Cells were transfected with Nrf2 siRNA. After $24 \mathrm{~h}$, the cells were treated with or without $500 \mu \mathrm{M}$ morin for $6 \mathrm{~h}$. The proteins were separated on SDS-polyacrylamide gels and then transferred onto nitrocellulose membranes. The membranes were probed with the specific antibodies against Nrf2, p-Nrf2, Keap1 and HO-1. Proteins were visualized using an enhanced chemiluminescence (ECL) detection system. Actin was used as an internal control. The relative ratios of expression in the western blotting results are shown at the bottom of each of the results as relative values to actin expression.

of morin and observed that the treatment of cells with morin timedependently increased the expression levels of phosphorylated Nrf2 (Fig. 4A). Additionally, western blot analysis was carried out using the nuclear and cytosolic fractions of the $\mathrm{C} 2 \mathrm{C} 12$ cells. The results shown in Fig. 5A and B indicate that the amounts of total and phosphorylated Nrf2 proteins in the nucleus were markedly increased following treatment with morin. The immunofluorescence images also revealed that the nuclear localization and accumulation of $\mathrm{Nrf} 2$ in the $\mathrm{C} 2 \mathrm{C} 12$ cells was significantly increased after stimulation with morin (Fig. 5C).

Nrf2-dependent induction of $\mathrm{HO}-1$ by morin in $\mathrm{C} 2 \mathrm{Cl}$ myoblasts. In order to provide evidence for the involvement of Nrf 2 in the induction of HO-1 by morin, we transiently transfected C2C12 cells with Nrf2 siRNA. Western blot analysis results revealed that the silencing of Nrf2 using specific siRNA abrogated the morin-induced increase and phosphorylation in
Nrf2 expression (Fig. 4B). Therefore, we investigated whether Nrf2 siRNA transfection attenuated morin-induced upregulation of HO-1 and downregulation of Keap1 and found that Nrf2 siRNA reversed these effects, which is evidence that the augmentation of HO-1 by morin was mediated by Nrf 2 .

Effect of extracellular signal-regulated kinase (ERK) signaling pathway on Nrf2-mediated HO-1 induction by morin in C2C12 myoblasts. To identify the upstream signaling events involved in morin-mediated Nrf2-dependent HO-1 induction, the potential involvement of the PI3K/Akt and MAPK signaling pathways was investigated. The total and phosphorylated levels of PI3K and Akt, a downstream target of PI3K, did not show a notable change in the morin-treated $\mathrm{C} 2 \mathrm{C} 12$ cells as compared with levels in the untreated control cells (Fig. 6). Subsequently, although there were no notable changes observed in the phosphorylated levels of c-Jun N-terminal kinase (JNK) and p38 MAPK, the activation of 
A

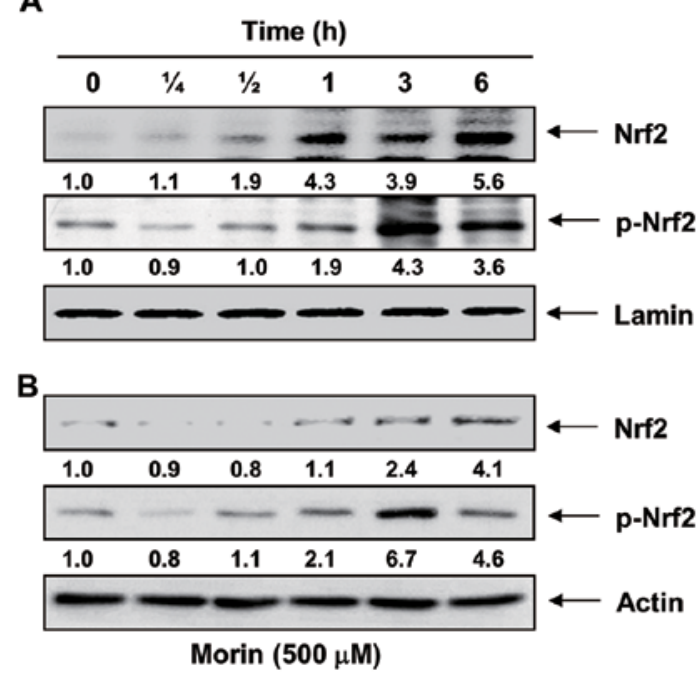

C

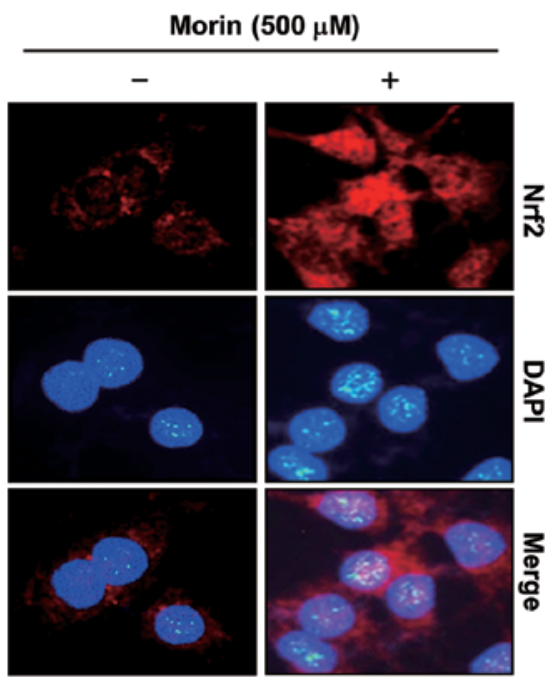

Figure 5. Morin enhances nuclear translocation of nuclear factor-erythroid 2-related factor 2 (Nrf2) in C2C12 myoblasts. (A and B) Cells were incubated with $500 \mu \mathrm{M}$ morin for the indicated time periods. (A) Nuclear or (B) cytosolic proteins were separated on sodium dodecyl sulfate (SDS)-polyacrylamide gels and then transferred onto nitrocellulose membranes. The membranes were probed with anti-Nrf2 and anti-p-Nrf2 antibodies. Proteins were visualized using an enhanced chemiluminescence (ECL) detection system. Lamin B and actin were used as the internal controls of nuclear and cytosolic proteins, respectively. The relative ratios of expression in the western blotting results are shown at the bottom of each of the results as relative values to lamin B (A) or actin (B) expression. (C) Cells were treated with $500 \mu \mathrm{M}$ morin for $6 \mathrm{~h}$ and then localization of Nrf2 was visualized with a fluorescence microscope after immunofluorescence staining with anti-Nrf2 antibody and an FITC-labeled anti-rabbit IgG antibody (red). Nuclei of the corresponding cells were visualized with DAPI (blue).

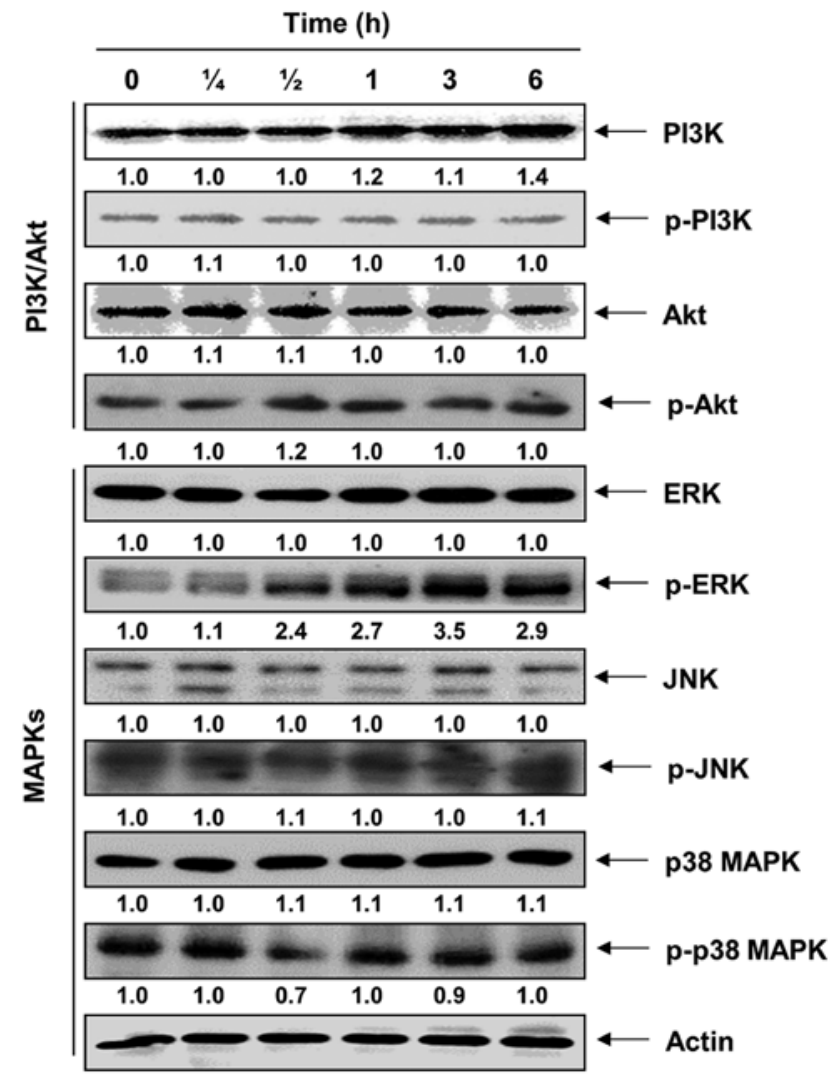

Figure 6. Morin induces phosphorylation of extracellular signal-regulated kinase (ERK) in C2C12 myoblasts. Cells were incubated with $500 \mu \mathrm{M}$ morin for the indicated time periods. The cells were lysed and then equal amounts of cell lysates were separated on sodium dodecyl sulfate (SDS)-polyacrylamide gels and transferred to nitrocellulose membranes. The membranes were probed with the indicated antibodies and then the proteins were visualized using an enhanced chemiluminescence (ECL) detection system. Actin was used as an internal control. The relative ratios of expression in the western blotting results are shown at the bottom of each of the results as relative values to actin expression.

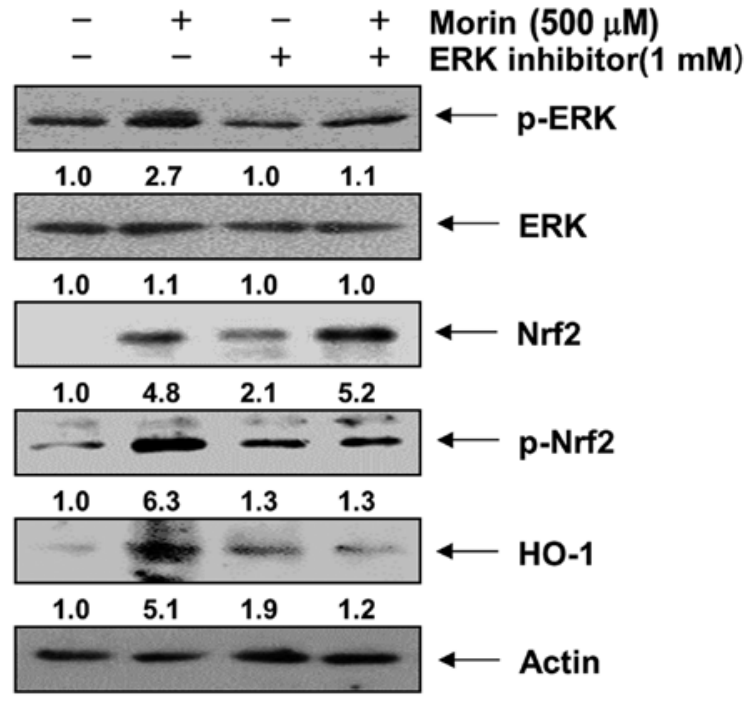

Figure 7. Morin phosphorylates nuclear factor-erythroid 2-related factor 2 (Nrf2) through extracellular signal-regulated kinase (ERK) activation in C2C12 myoblasts. Cells were pretreated for $1 \mathrm{~h}$ with or without PD98059, an inhibitor of ERK, and then treated with $500 \mu \mathrm{M}$ morin for an additional $6 \mathrm{~h}$. The cells were lysed and then equal amounts of cell lysates were separated on sodium dodecyl sulfate (SDS)-polyacrylamide gels and transferred to nitrocellulose membranes. The membranes were probed with the indicated antibodies, and the proteins were visualized using an enhanced chemiluminescence (ECL) detection system. Actin was used as an internal control. The relative ratios of expression in the western blotting results are shown at the bottom of each of the results as relative values to actin expression.

extracellular signal-regulated kinase (ERK) was noted as early as 30 min after morin treatment, and it lasted at least for $6 \mathrm{~h}$. However, treatment with a selective inhibitor of ERK, PD98059, blocked the morin-triggered phosphorylation of Nrf2, and HO-1 induction was accordingly diminished without the blockade of Nrf2 induction (Fig. 7). By contrast, when an inhibitor of ERK 
was utilized, the induction of the total protein level of Nrf 2 in the morin-treated $\mathrm{C} 2 \mathrm{C} 12$ cells was not attenuated.

\section{Discussion}

Although there have been few studies on how oxidative stress may quantitatively affect the load-carrying capacity of muscle cells, oxidative stress on myoblasts should accompany the dysfunction of muscles $(3,4)$. In this investigation, as part of the screening program for therapeutic antioxidative agents from phytochemicals, we attempted to determine whether morin offers protection from oxidative stress-induced cytotoxicity using a C2C12 myoblast cell model. We first observed that when $\mathrm{C} 2 \mathrm{C} 12$ myoblasts were treated with morin in the presence of $\mathrm{H}_{2} \mathrm{O}_{2}$, cell viability was significantly recovered by inhibiting $\mathrm{H}_{2} \mathrm{O}_{2}$-induced $\mathrm{ROS}$ generation, compared with exposure to $\mathrm{H}_{2} \mathrm{O}_{2}$ alone. Our data also showed that $\mathrm{H}_{2} \mathrm{O}_{2}$ exposure increased tail length and the expression of $\mathrm{p}-\gamma \mathrm{H} 2 \mathrm{AX}$, whereas each event was mitigated in $\mathrm{C} 2 \mathrm{C} 12$ cells that had been treated with morin prior to $\mathrm{H}_{2} \mathrm{O}_{2}$ exposure. As a result, these findings suggest that morin may be useful for the prevention of $\mathrm{H}_{2} \mathrm{O}_{2}$-induced cytotoxicity due to its strong antioxidant effect.

There is mounting evidence that oxidative stress is implicated in the pathogenesis of muscle dysfunction $(4,5)$. Oxidative stress occurs when the production of ROS exceeds its catabolism. ROS, including superoxide radical anions, hydroxyl radicals, singlet oxygen and hydrogen peroxide, are a class of endogenous signaling molecules with specific functions depending on their subcellular localization, local concentration and duration of production. Although a moderate level of ROS transiently oxidizes the cysteine sulfhydryl that contributes to the active sites of most proteins, when ROS accumulate to a certain level, the active effects may convert to inhibitory effects that damage cellular functions $(30,31)$. Excessive ROS generation in skeletal muscles can influence the contractile function of skeletal muscles by causing fatigue and increasing the oxidative damage to cells, which is implicated in the development of multiple diseases, including muscular dystrophy and sarcopenia $(4,5)$. Therefore, the discovery of an efficient agent that is able to reduce ROS is valuable in the treatment of muscle-related diseases. As expected, our results showed that ROS generation in $\mathrm{C} 2 \mathrm{C} 12$ myoblasts was significantly increased by $\mathrm{H}_{2} \mathrm{O}_{2}$ challenge and that morin markedly reduced ROS production by attenuating DNA damage.

Nrf2, a transcription factor that is part of the redox homeostatic gene regulatory network, and its repressor, Keapl, play indispensable roles in protecting a variety of tissues from a wide array of toxic insults, including oxidative stress. As yet, the role of Nrf2 signaling has not been well characterized in skeletal muscle. However, coordinated regulation of Nrf2 redox signaling is believed to preserve the redox state and to protect skeletal muscle structure and function $(2,32)$. Previous studies have shown that active skeletal muscle exhibit increased nuclear Nrf2 levels and subsequent activation of its major target antioxidant enzymes, including HO-1 (33). Contrary to this, the loss of Nrf2 is strongly coupled with the dysregulation of antioxidant pathways and the progression of muscle dysfunction $(34,35)$. Nrf2 is sequestered in the cytosol as an inactive complex with its repressor Keap1. Dissociation of Nrf2 from Keap1 is a prerequisite for nuclear translocation and subsequent DNA binding of Nrf2 to regulate the inducible expression of cytoprotective genes, such as that of HO-1 $(21,22)$. HO-1 is an inducible rate-limiting enzyme initially identified as a phase II detoxifying enzyme that facilitates the degradation of heme into bilirubin, free iron, and carbon monoxide. The final products of heme catabolism exert certain antioxidant effects by neutralizing intracellular ROS $(36,37)$. Therefore, Nrf2/HO-1 signaling may represent a potential therapeutic target in the management of oxidative stress-related diseases. In the present study, we observed a significant increase in total Nrf 2 expression in morin-treated $\mathrm{C} 2 \mathrm{C} 12$ myoblasts that was correlated with a concomitant reduction in Keap1 expression. Subsequently, we found that morin triggered the phosphorylation of $\mathrm{Nrf} 2$ and led to HO-1 induction along with a concomitant translocation of Nrf2 into the nuclei. Howevere, Nrf2-specific siRNA markedly suppressed morin-enhanced HO-1 protein levels, suggesting that $\mathrm{Nrf} 2$ is a critical upstream regulator of the morin-mediated induction of $\mathrm{HO}-1$ in $\mathrm{C} 2 \mathrm{C} 12$ myoblasts.

It has been proposed that the induction of phosphorylation plays a key role in the regulation of the transcriptional activity of Nrf2 $(23,24)$. In addition, a number of protein kinases, such as PI3K/Akt and MAPKs, have been implicated as upstream signals in the regulation of Nrf2 activity by facilitating the translocation of Nrf2 into the nucleus, whereupon it binds to ARE in the promoter regions (38-42). Therefore, to investigate whether any protein kinases may be involved in the activation of Nrf2, the phosphorylated level of different protein kinases following morin treatment was analyzed. Our results revealed that morin treatment only had a notable inducing effect on ERK phosphorylation within $30 \mathrm{~min}$. In contrast, phosphorylation of PI3K, Akt, JNK and p38 MAPK was not observed at any time point. Furthermore, our data indicated that morininduced phosphorylation of Nrf2 and induction of HO-1 were effectively inhibited by the ERK kinase inhibitor, whereas the increased total protein levels of Nrf2 were not affected. These observations suggest that morin may activate ERK by inducing its phosphorylation and in turn post-translationally phosphorylate Nrf2 as a downstream signal, which is required for Nrf2 accumulation in the nucleus leading to HO-1 expression.

In conclusion, our results showed that in $\mathrm{C} 2 \mathrm{C} 12$ myoblasts, morin exhibited protective ability against $\mathrm{H}_{2} \mathrm{O}_{2}$-induced cytotoxicity and DNA damage through the suppression of intracellular ROS generation. In addition, our overall results imply that morin may activate Nrf2 by activating ERK to contribute to the induction of phase II antioxidant HO-1 in $\mathrm{C} 2 \mathrm{C} 12$ myoblasts, which, at least in part, contributes to a cellular defense mechanism against oxidative stress-induced genotoxic events. In future studies, this molecular mechanism must be validated in vivo. A positive result, if confirmed, would be invaluable to the development of new approaches for effective stress-responsive antioxidants against assaults triggered by ROS.

\section{Acknowledgements}

This study was supported by the High Value-Added Food Technology Development Program (314043-3), Chinese Ministry of Agriculture, Food and Rural Affairs. 


\section{References}

1. Szczesny B, Olah G, Walker DK, Volpi E, Rasmussen BB, Szabo C and Mitra S: Deficiency in repair of the mitochondrial genome sensitizes proliferating myoblasts to oxidative damage. PLoS One 8: e75201, 2013.

2. Miller CJ, Gounder SS, Kannan S, Goutam K, Muthusamy VR, Firpo MA, Symons JD, Paine R III, Hoidal JR and Rajasekaran NS: Disruption of Nrf2/ARE signaling impairs antioxidant mechanisms and promotes cell degradation pathways in aged skeletal muscle. Biochim Biophys Acta 1822: 1038-1050, 2012

3. Ji LL, Gomez-Cabrera MC and Vina J: Exercise and hormesis: Activation of cellular antioxidant signaling pathway. Ann NY Acad Sci 1067: 425-435, 2006.

4. Powers SK and Jackson MJ: Exercise-induced oxidative stress: Cellular mechanisms and impact on muscle force production. Physiol Rev 88: 1243-1276, 2008.

5. Song W, Kwak HB and Lawler JM: Exercise training attenuates age-induced changes in apoptotic signaling in rat skeletal muscle. Antioxid Redox Signal 8: 517-528, 2006.

6. Harasym J and Oledzki R: Effect of fruit and vegetable antioxidants on total antioxidant capacity of blood plasma. Nutrition 30 : 511-517, 2014.

7. Guo W, Kong E and Meydani M: Dietary polyphenols, inflammation, and cancer. Nutr Cancer 61: 807-810, 2009.

8. Landete JM: Dietary intake of natural antioxidants: Vitamins and polyphenols. Crit Rev Food Sci Nutr 53: 706-721, 2013.

9. Hardigree AA and Epler JL: Comparative mutagenesis of plant flavonoids in microbial systems. Mutat Res 58: 231-239, 1978.

10. Wu TW, Zeng LH, Wu J and Fung KP: Morin: A wood pigment that protects three types of human cells in the cardiovascular system against oxyradical damage. Biochem Pharmacol 47: 1099-1103, 1994.

11. Kitagawa S, Sakamoto $\mathrm{H}$ and Tano $\mathrm{H}$ : Inhibitory effects of flavonoids on free radical-induced hemolysis and their oxidative effects on hemoglobin. Chem Pharm Bull (Tokyo) 52: 999-1001, 2004.

12. Liu YH, Mo SL, Bi HC, Hu BF, Li CG, Wang YT, Huang L, Huang M, Duan W, Liu JP, et al: Regulation of human pregnane $\mathrm{X}$ receptor and its target gene cytochrome P450 3A4 by Chinese herbal compounds and a molecular docking study. Xenobiotica 41: 259-280, 2011.

13. Yang SH, Choi HG,Lim SJ,Lee MG and Kim SH: Effects of morin on the pharmacokinetics of etoposide in 7,12-dimethylbenz[a] anthracene-induced mammary tumors in female Sprague-Dawley rats. Oncol Rep 29: 1215-1223, 2013.

14. Al Numair KS, Chandramohan G, Alsaif MA and Baskar AA: Protective effect of morin on cardiac mitochondrial function during isoproterenol-induced myocardial infarction in male Wistar rats. Redox Rep 17: 14-21, 2012.

15. Al-Numair KS, Chandramohan G, Alsaif MA, Veeramani $C$ and El Newehy AS: Morin, a flavonoid, on lipid peroxidation and antioxidant status in experimental myocardial ischemic rats. Afr J Tradit Complement Altern Medicines 11: 14-20, 2014.

16. Kim J, Kim JS and Park E: Cytotoxic and anti-inflammatory effects of onion peel extract on lipopolysaccharide stimulated human colon carcinoma cells. Food Chem Toxicol 62: 199-204, 2013.

17. Nandhakumar R, Salini K and Niranjali Devaraj S: Morin augments anticarcinogenic and antiproliferative efficacy against 7,12-dimethylbenz(a)-anthracene induced experimental mammary carcinogenesis. Mol Cell Biochem 364: 79-92, 2012.

18. Park JY, Kang KA, Kim KC, Cha JW, Kim EH and Hyun JW: Morin induces heme oxygenase-1 via ERK-Nrf2 signaling pathway. J Cancer Prev 18: 249-256, 2013.

19. Zhang Y and Gordon GB: A strategy for cancer prevention: Stimulation of the Nrf2-ARE signaling pathway. Mol Cancer Ther 3: 885-893, 2004.

20. Ishii T, Itoh $\mathrm{K}$, Takahashi $\mathrm{S}$, Sato $\mathrm{H}$, Yanagawa $\mathrm{T}$, Katoh $\mathrm{Y}$, Bannai S and Yamamoto M: Transcription factor Nrf2 coordinately regulates a group of oxidative stress-inducible genes in macrophages. J Biol Chem 275: 16023-16029, 2000.

21. Niture SK, Khatri R and Jaiswal AK: Regulation of Nrf2-an update. Free Radic Biol Med 66: 36-44, 2014.

22. Kobayashi M and Yamamoto M: Molecular mechanisms activating the Nrf2-Keap1 pathway of antioxidant gene regulation. Antioxid Redox Signal 7: 385-394, 2005.
23. Pi J, Bai Y, Reece JM, Williams J, Liu D, Freeman ML, Fahl WE, Shugar D, Liu J and Qu W: Molecular mechanism of human Nrf2 activation and degradation: Role of sequential phosphorylation by protein kinase CK2. Free Radic Biol Med 42: 1797-1806, 2007.

24. Apopa PL, He X and Ma Q: Phosphorylation of Nrf2 in the transcription activation domain by casein kinase 2 (CK2) is critical for the nuclear translocation and transcription activation function of Nrf2 in IMR-32 neuroblastoma cells. J Biochem Mol Toxicol 22: 63-76, 2008.

25. Eom SA, Kim DW, Shin MJ, Ahn EH, Chung SY, Sohn EJ, Jo HS, Jeon SJ, Kim DS, Kwon HY, et al: Protective effects of PEP-1catalase on stress-induced cellular toxicity and MPTP-induced Parkinson's disease. BMB Rep 48: 395-400, 2015.

26. Park MH and Han JS: Padina arborescens extract protects high glucose-induced apoptosis in pancreatic $\beta$ cells by reducing oxidative stress. Nutr Res Pract 8: 494-500, 2014.

27. Jeong MH, Yang K, Lee CG, Jeong DH, Park YS, Choi YJ, Kim JS, Oh SJ, Jeong SK and Jo WS: In vitro genotoxicity assessment of a novel resveratrol analogue, HS-1793. Toxicol Res 30: 211-220, 2014.

28. Jiang R, Teng Y, Huang Y, Gu J, Ma L, Li M and Zhou Y: Preeclampsia serum-induced collagen I expression and intracellular calcium levels in arterial smooth muscle cells are mediated by the PLC- $\gamma 1$ pathway. Exp Mol Med 46: e115, 2014.

29. Rogakou EP, Pilch DR, Orr AH, Ivanova VS and Bonner WM: DNA double-stranded breaks induce histone H2AX phosphorylation on serine 139. J Biol Chem 273: 5858-5868, 1998.

30. Kregel KC and Zhang HJ: An integrated view of oxidative stress in aging: Basic mechanisms, functional effects, and pathological considerations. Am J Physiol Regul Integr Comp Physiol 292: R18-R36, 2007.

31. Finkel T: Signal transduction by reactive oxygen species. J Cell Biol 194: 7-15, 2011

32. Li M and Fukagawa NK: Age-related changes in redox signaling and VSMC function. Antioxid Redox Signal 12: 641-655, 2010.

33. Safdar A, deBeer J and Tarnopolsky MA: Dysfunctional Nrf2-Keap1 redox signaling in skeletal muscle of the sedentary old. Free Radic Biol Med 49: 1487-1493, 2010.

34. Rangasamy T, Guo J, Mitzner WA, Roman J, Singh A, Fryer AD, Yamamoto M, Kensler TW, Tuder RM, Georas SN, et al: Disruption of Nrf2 enhances susceptibility to severe airway inflammation and asthma in mice. J Exp Med 202: 47-59, 2005.

35. Reddy NM, Kleeberger SR, Kensler TW, Yamamoto M, Hassoun PM and Reddy SP: Disruption of Nrf2 impairs the resolution of hyperoxia-induced acute lung injury and inflammation in mice. J Immunol 182: 7264-7271, 2009.

36. Katori M, Anselmo DM, Busuttil RW and Kupiec-Weglinski JW: A novel strategy against ischemia and reperfusion injury: Cytoprotection with heme oxygenase system. Transpl Immunol 9: 227-233, 2002.

37. Motterlini R and Foresti R: Heme oxygenase- 1 as a target for drug discovery. Antioxid Redox Signal 20: 1810-1826, 2014.

38. Bryan HK, Olayanju A, Goldring CE and Park BK: The Nrf2 cell defence pathway: Keap1-dependent and -independent mechanisms of regulation. Biochem Pharmacol 85: 705-717, 2013.

39. Chen HH, Chen YT, Huang YW, Tsai HJ and Kuo CC: 4-Ketopinoresinol, a novel naturally occurring ARE activator, induces the Nrf2/HO-1 axis and protects against oxidative stressinduced cell injury via activation of PI3K/AKT signaling. Free Radic Biol Med 52: 1054-1066, 2012.

40. Sun Z, Huang Z and Zhang DD: Phosphorylation of Nrf2 at multiple sites by MAP kinases has a limited contribution in modulating the Nrf2-dependent antioxidant response. PLoS One 4: e6588, 2009.

41. Shen G, Hebbar V, Nair S, Xu C, Li W, Lin W, Keum YS, Han J, Gallo MA and Kong AN: Regulation of Nrf2 transactivation domain activity. The differential effects of mitogen-activated protein kinase cascades and synergistic stimulatory effect of Raf and CREB-binding protein. J Biol Chem 279: 23052-23060, 2004.

42. Nguyen T, Sherratt PJ, Huang HC, Yang CS and Pickett CB: Increased protein stability as a mechanism that enhances Nrf2-mediated transcriptional activation of the antioxidant response element. Degradation of Nrf2 by the $26 \mathrm{~S}$ proteasome. J Biol Chem 278: 4536-4541, 2003. 